\title{
INFLUENCE OF INCLUSIVE AND SEGREGATIVE PHYSICAL EDUCATION FOR SCHOOLCHILDREN OF DIFFERENT MEDICAL GROUPS
}

\author{
Ivanna Bodnar \\ Lviv State University of Physical Culture, Ukraine \\ Iuliia Pavlova \\ Lviv State University of Physical Culture, Ukraine \\ Romana Sirenko \\ Lviv State University of Physical Culture, Ukraine \\ Ihor Lapychak \\ Lviv State University of Physical Culture, Ukraine
}

\begin{abstract}
The study aimed to compare the effectiveness of inclusive and segregative physical education classes for students of various medical groups, taking into account sociopsychological indicators and indicators of psychoemotional state. The study involved 1,414 schoolchildren aged 10-16 years $(M=12.7, S D=1.6)$. Through the survey, pupils' wellbeing, needs, motivations, and motor preferences at their leisure and physical education classes, level of situational and personal anxiety, degree of integration of the group, and motivation for success were ascertained. Data comparisons were made between schoolchildren who studied in segregated and inclusive ways of organizing physical education in schools. Attitudes towards schoolchildren's physical education and leisure patterns make it possible to assert that an inclusive model is effective. Integrative physical education classes are less mentally traumatic, more convenient, and psychologically comfortable than segregative ones. The way physical education is organized does not affect the level of anxiety and the class's degree of motivation in achieving success in schoolchildren's activities. Positive changes in the integrative conditions in the mental state come with all schoolchildren, but they are most noticeable among schoolchildren with low functional reserve capabilities.
\end{abstract}

Keywords: inclusion, mental state, physical education, schoolchildren.

\section{Introduction}

Inclusive education is slowly being introduced in secondary schools in Ukraine. Its concept has noble slogans and objectives (Wilhelmsen \& Sørensen, 2017; Wang, 2019). However, the individualized curricula of children who require inclusive education do not provide for physical education classes. Today, it is commonly known about the many positive effects of optimal physical activity 
Bodnar et al., 2021. Influence of Inclusive and Segregative Physical Education for Schoolchildren of Different Medical Groups

levels for persons of all ages, genders, and, in particular, health (Uher \& Bukova, 2018; Rogowska et al., 2020). It is possible to assume that specialists' methodological work and the experience of organizing lessons in special educational institutions are not easily introduced into the practice of inclusive physical education of children with special educational needs in secondary schools (Bodnar \& Prystupa, 2014).

Under the Salamanca Statement, orphans, children of migrants or displaced people, HIV-positive persons, pregnant adolescents, members of religious, ethnic, linguistic, etc. minorities also have special educational needs. Schoolchildren talented in the hard or soft sciences, who are creatively or artistically gifted, or who are athletically gifted, also require a differentiated approach in their studies. However, these categories of children rarely receive attention; inclusive education excludes them from its field of competence without considering the high social importance of the development of gifted persons. Given this, certain clarifications and distinctions are essential, as is the case for inclusive education in a narrow and broad sense (Qi \& Ha, 2012; Lleixà \& Nieva, 2020). The modern wellestablished public form of inclusive education (as education of children with special physical and psychological/developmental needs or detected disorders of health condition or various functional reserve capabilities) would be consistent with a narrow understanding of this phenomenon. Inclusive education, in its broader sense, should include differentiation of educational services (Hodge et al., 2009), taking into account the full range of characteristics of children, as called for in the Salamanca Declaration. This updated understanding of the concept of inclusive education makes it clear that the division of schoolchildren into medical groups and the differentiation of a load of physical education classes, taking into account the child's functional reserve capacity, also apply to this concept. Inclusive education has the potential to replace the long-standing system of conditional division into medical groups, which is typical of the Ukrainian system of physical education in schools.

In Ukraine, the main criterion for dividing schoolchildren into medical groups is based on the Ruffier's test results: schoolchildren with high and aboveaverage levels of functional reserve capacities of the cardiovascular system are directed to the main medical group, with an average level - to the preparatory medical group, schoolchildren with low and below-average levels - to the special medical group (Bodnar, 2013). Schoolchildren with specific minor health problems are also included in the special medical group. According to the normative documents, pupils of the main medical group study one physical education curriculum together with pupils of the preparatory medical group. The special medical group takes part in the preparatory and final part of the physical education class. During the main part of the lesson, they do only those exercises that are not contraindicated to their health; this group of pupils will learn more 
about the curriculum's content in additional physical education classes. Unfortunately, nowadays, due to a lack of resources, only some Ukrainian schools have followed these recommendations, and most schools have segregated classes with children of different medical groups, which provide for differentiation of physical load depending on the level of their functional reserve capacities. Thus, in Ukraine, there are two models of the organization of physical education inclusive and segregated - which operate simultaneously.

The special literature provides only some data on the effectiveness of segregated or inclusive physical education. It has been proved that inclusive physical education is effective in terms of physical activity levels of low, medium, and high intensity (Pavlova, 2015; Pavlova, et al., 2016). However, the analysis of physical fitness indices does not determine one of these models' preferences. Quite ambiguous conclusions regarding the advantages of this or that model were obtained considering gender, age, level of functional reserve capacities, and individual physical qualities of children (Bodnar \& Prystupa, 2014). There is a lack of groundwork concerning the influence of the inclusive model of physical education on the psychological performance of schoolchildren.

The study aimed to compare the effectiveness of inclusive and segregated physical education classes for schoolchildren in different medical groups, taking into account socio-psychological and psychosocial indicators.

\section{Methods}

\section{Study sample}

The study involved 1414 schoolchildren aged 10-16 (M=12.7, SD=1.6). Schoolchildren studied in grades 5-9 in 9 Ukrainian secondary schools and were sent for health reasons to medical groups. All subjects and their parents gave their informed consent for inclusion before they participated in the study. The study was conducted following the Declaration of Helsinki, and the protocol was approved by the Bioethics Committee of Lviv State University of Physical Culture.

\section{Research tools}

A survey of schoolchildren was conducted to ascertain their wellbeing, needs, motives, and motor preferences at leisure and physical education classes. The level of situational and personal anxiety was determined by Spielberg's method (Spielberger, et al., 1983); respondent's wellbeing and activity according to the "Wellbeing - Activity - Mood" test (Kokun, et al., 2011), the degree of group integration - according to the index of cohesion of K. Seashore (Axverdova, Gjulushanjan, \& Kolenkina, 2006); motivation for success - by the method of V. A. Rozanova (Rozanova, 1999). 
Bodnar et al., 2021. Influence of Inclusive and Segregative Physical Education for Schoolchildren of Different Medical Groups

\section{Organization of the study}

Comparisons were made between schoolchildren in a segregated and inclusive school environment. Observations were taken at the beginning and the end of the school year. Obtained results in some cases were analysed taking into account the type of medical group (main, preparatory, special).

The experimental group (EG, $\mathrm{n}=694,46.11 \%$ - females) was composed of schoolchildren who attended school under inclusive conditions. In these educational institutions, physical education classes for students of different health states were conducted simultaneously, that is, children with different levels of functional reserve capacities were engaged together, however, by differentiating/individualizing tasks. The needs and capacities of each child were considered as well. In the control group (CG, $n=720,48.05 \%$ - females), physical education for schoolchildren in main and preparatory medical groups was conducted separately from the special medical group (segregated - the class was held in different halls, at different times).

\section{Statistical analysis}

The IBM SPSS Statistics V. 23 was used for the statistical processing of data. The mean (M), and corrected standard deviation (SD) were determined. The Student's t-test was used to compare unrelated samples. The validity of the difference between the results of CG and the EG was determined by $\chi^{2}$-test. The differences were considered to be significant at least when $\mathrm{p} \leq 0.05$.

\section{Results}

Needs, motives, and motor preferences at leisure.

Schoolchildren of the EG are more likely to help parents (by 12.8\%, $<<0.01$ ), spend more time walking (by $10.9 \%, \mathrm{p}<0.01$ ) than those in the CG. This group (EG) also spent $11.1 \%$ more time $(p<0.01)$ on computer entertainment and social networking; visited exhibitions, museums, theatres, etc., more frequently (by $8.5 \%, \mathrm{p}<0.01$ ). On the other hand, schoolchildren of the CG more often attended sports competitions as spectators and participated directly in hiking (by $4.1 \%$ $\mathrm{p}>0.05 ; 1.4 \%, \mathrm{p}>0.05$, respectively).

Schoolchildren of the CG who were assigned to the main medical group (by $7.8 \%, \mathrm{p}=0.05$ ) and the special medical group (by 31.8\%, $\mathrm{p}=0.07$ ) of the CG more often in comparison with students of the EG devoted time to reading the curriculum and fiction. In contrast, the EG students preferred searching data on the Internet. The difference between the number of active computer users among the EG and the CG students was also close to the statistically significant value $(p=0.07)$, so we can assume that the EG students found the information necessary for learning on the Internet. 
The analysis of the favourite physical activity at leisure showed that students of the CG like (by 15.5\%, $\mathrm{p}<0.001$ ) to participate in sports games less. Schoolchildren of the CG (in particular a special medical group) more often (by $45.5 \%, \mathrm{p}<0.05$ ) chose physical activities such as billiards, bowling, and various kinds of fitness at their leisure time. Schoolchildren of the CG (special medical group) were $26.1 \%$ more likely ( $\mathrm{p}=0.05$ ) to exercise on simulators.

Needs, motivation, and motor preferences of schoolchildren at physical education classes.

Schoolchildren of the CG were less likely (by $18.0 \%, \mathrm{p}<0.001$ ) to feel positive emotions, vivacity, and improved mood in physical education classes. There were differences in performance of students in the main medical group, including the fact that more students of the EG considered PE classes as an opportunity to rest after mental loads $(13.7 \%, \mathrm{p}<0.05)$ and to socialize (by $7.6 \%$, $\mathrm{p}<0.05)$.

In addition to the desire to improve health (the relative number of schoolchildren in the EG - 62.7\%, and the CG - 49.9\%) and increase the level of physical fitness (28.9\% of the EG and $38.4 \%$ of the CG), among the factors that motivate participation in the PE classes was a desire to have a good time, have fun, get positive emotions ( $40.6 \%$ of the EG students and $44.2 \%$ of the CG students), rest after mental work (48.7\% of the EG students, and $45.3 \%$ of the CG students), and improve wellbeing (42.1\% of the EG students, and $32.2 \%$ of the CG students) (Table 1). In general, differences were found between the motivational priorities "improve health" and "improve wellbeing" of the EG and the CG students. The EG students often $(\mathrm{p}<0.05)$ noted that the PE classes' attendance was important to them for this very reason.

Table 1 Motives That Encourage Students to Participate in Physical Education Classes

\begin{tabular}{|l|c|c|c|c|}
\hline \multirow{2}{*}{ Motives } & \multicolumn{2}{|c|}{ Relative number of persons, \% } & \multirow{2}{*}{ P } \\
\cline { 2 - 4 } & EG & CG & $\begin{array}{c}\text { differences } \\
\text { between EG } \\
\text { and CG }\end{array}$ & \\
\hline Health improving relax after intellectual & 48.7 & 45.3 & 3.4 & - \\
\hline $\begin{array}{l}\text { Opportunity to relads } \\
\text { loads }\end{array}$ & 11.9 & 11.5 & 0.4 & - \\
\hline Communication & 9.1 & 8.7 & 0.5 & - \\
\hline $\begin{array}{l}\text { Opportunity to gain knowledge, learn } \\
\text { something new }\end{array}$ & 32.7 & 29.7 & 3 & - \\
\hline $\begin{array}{l}\text { Improve the appearance } \\
\text { Improvement of mental working } \\
\text { capacity }\end{array}$ & 28.9 & 38.4 & -9.5 & - \\
\hline
\end{tabular}


Bodnar et al., 2021. Influence of Inclusive and Segregative Physical Education for Schoolchildren of Different Medical Groups

\begin{tabular}{|l|c|c|c|c|}
\hline Possibility to have fun & 9.4 & 9.6 & -0.1 & - \\
\hline $\begin{array}{l}\text { Possibility to receive positive emotions } \\
\text { self-realization }\end{array}$ & 40.6 & 44.2 & -3.6 & - \\
\hline Self-realization, & 8.1 & 5.1 & 3 & - \\
\hline Improve wellbeing & 42.1 & 32.2 & 9.9 & 0.035 \\
\hline
\end{tabular}

The analysis of the survey results did not reveal significant differences in the reasons why schoolchildren did not like the PE classes. The main reason given by students in both groups was that they were not interested in exercising during classes.

The CG students skipped PE classes more often (by $9.2 \%, \mathrm{p}<0.05$ ) than the EG students. A doctor's medical certificate was the most common reason for missing PE classes among the EG schoolchildren (48.0\%). In comparison, the CG students could skip PE classes due to deteriorating health (46.0\%), muscle or abdominal pain (30.0\%), although they did not have any certificate from a medical specialist.

Schoolchildren in the EG were more likely to complain of their health; among the most common were complaints of pain in the joints, spine during prolonged standing or sitting $(7.0 \%, \mathrm{p}<0.05)$ and eye discomfort, either during or after classes, or decreased visual acuity $(5.8 \%, \mathrm{p}<0.05)$.

\section{Characterization of psycho-emotional state}

The number of persons with high levels of personal anxiety was higher in the CG $(p<0.05)$. In the EG schoolchildren, the personal anxiety level was moderate, while it was high in the CG. High indices on the sub-scales "Wellbeing" and "Mood" were more often observed in the EG students (three times more often in the preparatory medical group) and on the scale "Activity" (twice more often in the special medical group) (Table 2).

Table 2 Indicators of Psycho-emotional State $(M \pm S D)$ of Students of Different Medical Groups (1 - main, 2 - preparatory, 3 - special, 4 - generalized results)

\begin{tabular}{|c|c|c|c|c|c|c|c|c|}
\hline & & & & & cators & & & \\
\hline & & & & ety & & & & \\
\hline & & for success & $\begin{array}{l}\text { situa- } \\
\text { tional }\end{array}$ & personal & being & vity & Mood & cohesion \\
\hline & EG & $\begin{array}{c}128.43 \pm \\
23.40 \\
\end{array}$ & $\begin{array}{c}30.33 \pm \\
4.84 \\
\end{array}$ & $\begin{array}{c}47.60 \pm \\
14.94 \\
\end{array}$ & $\begin{array}{c}5.51 \pm \\
1.46\end{array}$ & $\begin{array}{c}4.82 \pm \\
1.42 \\
\end{array}$ & $\begin{array}{c}5.71 \pm \\
1.34 \\
\end{array}$ & $\begin{array}{c}14.45 \pm \\
2.66 \\
\end{array}$ \\
\hline 1 & KG & $\begin{array}{c}149.25 \pm \\
25.66\end{array}$ & $\begin{array}{c}28.73 \pm \\
5.98\end{array}$ & $\begin{array}{c}46.77 \pm \\
11.89\end{array}$ & $\begin{array}{c}6.22 \pm \\
0.95\end{array}$ & $\begin{array}{c}5.27 \pm \\
1.61\end{array}$ & $\begin{array}{c}6.43 \pm \\
0.51\end{array}$ & $\begin{array}{c}12.96 \pm \\
1.8\end{array}$ \\
\hline & $p$ & 0.001 & 0.142 & 0.447 & 0.206 & 0.125 & 0.159 & 0.377 \\
\hline 2 & EG & $\begin{array}{c}121.50 \pm \\
26.66\end{array}$ & $\begin{array}{c}26.75 \pm \\
8.29\end{array}$ & $\begin{array}{c}43.75 \pm \\
10.18\end{array}$ & $\begin{array}{c}5.53 \pm \\
1.72\end{array}$ & $\begin{array}{c}4.56 \pm \\
1.74\end{array}$ & $\begin{array}{c}5.87 \pm \\
1.68\end{array}$ & $\begin{array}{c}9.37 \pm \\
1.53\end{array}$ \\
\hline
\end{tabular}




\begin{tabular}{|c|c|c|c|c|c|c|c|c|}
\hline & KG & $\begin{array}{c}120.86 \pm \\
22.41\end{array}$ & $\begin{array}{c}31.33 \pm \\
3.50\end{array}$ & $\begin{array}{c}45.67 \pm \\
21.09\end{array}$ & $\begin{array}{c}6.5 \pm \\
0.5\end{array}$ & $\begin{array}{c}5.87 \pm \\
1.1\end{array}$ & $\begin{array}{c}6.67 \pm \\
0.23\end{array}$ & $\begin{array}{c}9.19 \pm \\
1.36\end{array}$ \\
\hline & $p$ & 0.135 & 0.991 & 0.631 & 0.005 & 0.237 & 0.003 & 0.911 \\
\hline \multirow{3}{*}{3} & EG & $\begin{array}{c}125.90 \pm \\
25.11\end{array}$ & $\begin{array}{c}29.42 \pm \\
6.10\end{array}$ & $\begin{array}{c}44.92 \pm \\
14.39\end{array}$ & $\begin{array}{c}5.51 \pm \\
1.46\end{array}$ & $\begin{array}{c}4.82 \pm \\
1.42\end{array}$ & $\begin{array}{c}5.71 \pm \\
1.34\end{array}$ & $\begin{array}{c}14.45 \pm \\
2.66\end{array}$ \\
\hline & KG & $\begin{array}{c}145.75 \pm \\
28.78\end{array}$ & $\begin{array}{c}29.25 \pm \\
7.67\end{array}$ & $\begin{array}{c}46.73 \pm \\
11.92\end{array}$ & $\begin{array}{c}6.22 \pm \\
0.95\end{array}$ & $\begin{array}{c}5.27 \pm \\
1.61\end{array}$ & $\begin{array}{c}6.43 \pm \\
0.51\end{array}$ & $\begin{array}{c}12.96 \pm \\
1.8\end{array}$ \\
\hline & $p$ & 0.607 & 0.649 & 0.249 & 0.018 & 0.473 & 0.004 & 0.627 \\
\hline \multirow{3}{*}{4} & EG & $\begin{array}{c}122.25 \\
27.67\end{array}$ & $\begin{array}{c}27.68 \\
7.35\end{array}$ & $\begin{array}{l}46.63 \\
12.01\end{array}$ & $\begin{array}{l}53.79 \\
14.91\end{array}$ & $\begin{array}{l}45.90 \\
14.22\end{array}$ & $\begin{array}{l}55.96 \\
14.69\end{array}$ & $\begin{array}{c}10.62 \\
3.68\end{array}$ \\
\hline & EG & $\begin{array}{c}125.03 \\
26.49\end{array}$ & $\begin{array}{c}28.05 \\
6.93\end{array}$ & $\begin{array}{l}47.16 \\
12.13\end{array}$ & $\begin{array}{l}50.48 \\
16.83\end{array}$ & $\begin{array}{l}46.25 \\
15.82\end{array}$ & $\begin{array}{l}51.97 \\
17.68\end{array}$ & $\begin{array}{c}10.57 \\
3.60\end{array}$ \\
\hline & $\mathrm{p}$ & 0.347 & 0.645 & 0.702 & 0.025 & 0.697 & 0.008 & 0.868 \\
\hline
\end{tabular}

The motivation for success among schoolchildren of various groups was hardly different. Only students of the main medical group who belonged to the EG were significantly more $(\mathrm{p}<0.001)$ motivated for success. This suggests that inclusive learning environments effectively develop the motivation to achieve success only in schoolchildren with a high level of functional reserve capacities.

An analysis of the index values of the student's degree of integration showed no students who considered the class's cohesion to be low or below the average level.

\section{Discussion}

Before introducing PE into secondary schools for inclusive children, it is relevant to compare the effectiveness of inclusive and segregated PE classes and to weigh the risks and benefits of each form for the students of each of the three medical groups. In practice, inclusive physical education in the form of differentiated PE classes (with different medical groups, as well) has existed for a long time (Haycock \& Smith, 2010; Bertills, Granlund, \& Augustine, 2019). Because the division into medical groups, declared by regulatory documents, but not financially supported, "works" solely on paper (only those few schools that have resolved the issue of paying two teachers per each one PE class for children of different medical groups conduct separate lessons). Therefore, almost every PE teacher has already got some experience in selecting flexible teaching methods and organization of educational environment for students in the same class with substantial reserve capacities, which are particularly acute during the classes (Smith, 2004; Hodge et al., 2009; Rekaa, Hanisch, \& Ytterhus, 2019). However, the introduction of physical education in secondary schools requires a comparison of the effectiveness of inclusive and segregated lessons for each of the three medical groups, particularly the analysis of risks and benefits. 
Bodnar et al., 2021. Influence of Inclusive and Segregative Physical Education for Schoolchildren of Different Medical Groups

Several social and psychological indicators are not affected by how the PE class is organized in secondary school. Along with this, there have been identified many differences in the social and psychological characteristics of students from different medical groups of the EG, which were formed under the influence of participation in inclusive classes. These features of attitude towards the PE and the structure of the recreational activities of integrated students make it possible to assert that this model is more effective since it helps to establish the prerequisites for the development of such essential qualities in students, as the ability to cooperate, responsibility, responsiveness, sociability, mobility of thought, etc.

Students in the EG spent more time on computer entertainment and social networking. To determine the reason for this difference in school behavior, further research should be undertaken with the aim to find out why students of the EG need more time to meet their needs in communication: whether inclusive classes increase this need, or vice a versa, do not contribute to the level of their satisfaction (Reiner, Niermann, Jekauc, \& Woll, 2013). Schoolchildren who studied in a segregated environment perceived PE classes as uninteresting, monotonous, and joyless work on improving physical qualities, which is rarely effective.

Therefore, the promotion of physical education among schoolchildren with a high level of functional reserve capacities can be recommended with an emphasis on recreation and communication at PE classes. General PE classes (for the whole class) are more conducive to fulfilling children's need for communication during physical activity (Edmunds, Biggs, \& Goldie, 2013; Fibbins, Ward, Watkins, Curtis, \& Rosenbaum, 2018).

More schoolchildren in the CG missed classes due to illness and did not have a medical certificate. This indicates that students with disabilities are more likely to be ill in the separate PE classes, and health complaints may be related to a reluctance to study. A factor that causes a negative change in the mental condition of schoolchildren who have studied under the segregated model can be the fact of a break with friends or the unfavourable psychological atmosphere in the classroom, leading to frustration (Biddle \& Asare, 2011).

The level of anxiety in the EG students was lower than in the CG students. This indicates that schoolchildren with disabilities and limited functional reserve capacities, despite studying in an inclusive model with children who had a higher level of physical fitness, did not perceive this situation as uncomfortable, threatening, or humiliating for their dignity.

Schoolchildren involved in the PE inclusive classes felt more comfortable, energetic, and initiative than children who were separated from their peers with a higher level of health and fitness. Therefore, it can be argued that an inclusive model of physical education in schools ensures a high level of psychological 
comfort for children. The intensity and quality of the interaction of children with low mental and physical capacities with the social environment in an inclusive environment increase substantially (Biddle \& Asare, 2011; Rekaa, Hanisch, \& Ytterhus, 2019).

Positive changes in the integrative conditions in the mental state occur in all schoolchildren; however, they are most noticeable among schoolchildren with health problems and deviations in functional reserve capacities: such children perceive physical education classes favourably, they feel safe; therefore, they are calm, and at the same time more initiative and more active. Therefore, integrative physical education classes in schools are more effective than segregated ones, particularly for children from primary and special medical groups.

\section{Conclusions}

The obtained results do not allow to unambiguously interpret the effectiveness of integrative or segregative type of learning. Additional research is needed to assess which type of training provides a more positive impact in terms of various aspects of health (physical, mental, social, etc.). However, according to the results obtained, some facts can be stated. Inclusive education has several advantages over the long-standing segregated system of conditional separation into medical groups, which is a feature of the Ukrainian system of physical education in schools:

- $\quad$ an inclusive model of PE is more efficient in terms of needs, motives, and motor preferences of students at leisure and during physical education classes;

- despite the indicators of schoolchildren's psycho-emotional state, the integrated PE classes are more effective than segregated ones. The PE integrated classes are more psychologically comfortable and less traumatic than segregated ones to a greater extent for students with average and lower than average levels of functional reserve capacities.

\section{References}

Ahverdova, O. A., Gjulushanjan, K. S., \& Kolenkina, V. V. (2006). Praktikum po social'noj psihologii. Moskva, TC Sfera.

Bertills, K., Granlund, M., \& Augustine, L. (2019). Inclusive Teaching Skills and Student Engagement in Physical Education. Frontiers in Education, 4, 74. https://doi.org/10.3389/feduc.2019.00074

Biddle, S. J. H., \& Asare, M. (2011). Physical activity and mental health in children and adolescents: A review of reviews. British Journal of Sports Medicine, 45(11), 886-895. https://doi.org/10.1136/bjsports-2011-090185

Bodnar, I. (2013). Dynamics of dextery, speed, explosive force, and flexibility indices in 
Bodnar et al., 2021. Influence of Inclusive and Segregative Physical Education for Schoolchildren of Different Medical Groups

schoolchildren belonging to different medical groups. Fizichna aktivnist', zdorov'ia i sport, 4(14), 13-22.

Bodnar, I., \& Prystupa, E. (2014). Efficiency of inclusive physical education lessons for schoolchildren with minor deviations in health. Postepy reabilitacji, 3, 13-19.

Edmunds, S., Biggs, H., \& Goldie, I. (2013). Let's get physical: The impact of physical activity on wellbeing. Mental Health Foundation, 38, 1-47.

Fibbins, H., Ward, P. B., Watkins, A., Curtis, J., \& Rosenbaum, S. (2018). Improving the health of mental health staff through exercise interventions: a systematic review. Journal of Mental Health, 27(2), 184-191. https://doi.org/10.1080/09638237.2018.1437614

Haycock, D., \& Smith, A. (2010). Inclusive physical education? A study of the management of national curriculum physical education and unplanned outcomes in England. British Journal of Sociology of Education, 31(3), 291-305. https://doi.org/10.1080/ 01425691003700532

Hodge, S., Ammahb, J. O. A., Casebolt, K. M., LaMaster, K., Hersman, B., Samalot-Rivera, A., \& Sato, T. (2009). A diversity of voices: Physical education teachers' beliefs about inclusion and teaching students with disabilities. International Journal of Disability, Development and Education, 56(4), 401-419. https://doi.org/10.1080/ 10349120903306756

Kokun, O. M., Pishko, I. O., Lozins`ka, N. S., Kopany`cya, O. V., \& Malxazov, O. R. (2011). Zbirny`k metody `k dlya diagnosty `ky` psy`xologichnoyi gotovnosti vijs `kovosluzhbovciv vijs `kovoyi sluzhby' za kontraktom do diyal'nosti u skladi my`rotvorchy`x pidrozdiliv. Kyiv.

Lleixà, T., \& Nieva, C. (2020). The social inclusion of immigrant girls in and through physical education. Perceptions and decisions of physical education teachers. Sport, Education and Society, 25(2), 185-198. https://doi.org/10.1080/13573322.2018.1563882

Qi, J., \& Ha, A. S. (2012). Inclusion in Physical Education: A review of literature. International Journal of Disability, Development and Education, 59(3), 257-281. https://doi.org/ 10.1080/1034912X.2012.697737

Pavlova, I. (2015). Life quality and health of children and youth of Ukraine. Slobozhanskyi Herald of Science and Sport, 46(2), 148-153. https://doi.org/10.15391/snsv.2015-2.029

Pavlova, I., Vynogradskyi, B., Ripak, I., Zikrach, D., \& Borek, Z. (2016). Prognostication of health-related life quality of Ukrainian residents due to physical activity level. Journal of Physical Education and Sport, 16(2), 418-423. https://doi.org/10.7752/jpes.2016.02065

Reiner, M., Niermann, C., Jekauc, D., \& Woll, A. (2013). Long-term health benefits of physical activity-a systematic review of longitudinal studies. BMC Public Health, 13, 813. https://doi.org/10.1186/1471-2458-13-813

Rekaa, H., Hanisch, H., \& Ytterhus, B. (2019). Inclusion in Physical Education: Teacher Attitudes and Student Experiences. A Systematic Review. International Journal of Disability, Development and Education, 66(1), 36-55. https://doi.org/10.1080/ 1034912X.2018.1435852

Rogowska, A. M., Pavlova, I., Kuśnierz, C., Ochnik, D., Bodnar, I., \& Petrytsa, P. (2020). Does Physical Activity Matter for the Mental Health of University Students during the COVID19 Pandemic? Journal of Clinical Medicine, 9(11), 3494. https://doi.org/10.3390/ jcm9113494

Rozanova, V. A. (1999). Psihologija upravlenija. Moskva, ZAO “Biznes-shkola "Intel-Sintez”.

Smith, A. (2004). The inclusion of pupils with special educational needs in secondary school physical education. Physical Education \& Sport Pedagogy, 9(1), 37-54. https://doi.org/10.1080/1740898042000208115 
Spielberger, C. D., Gorsuch, R. L., Lushene, R., Vagg, P. R., \& Jacobs, G. A. (1983). Manual for the State-Trait Anxiety Inventory. Palo Alto, CA: Consulting Psychologists Press.

Uher, I., \& Bukova, A. (2018). Interrelationship between Exercise and Diseases in young people: Review study. Physical Activity Review, 6, 203-212. https://doi.org/10.16926/ par.2018.06.25

Wang, L. (2019). Perspectives of students with special needs on inclusion in general physical education: A social-relational model of disability. Adapted Physical Activity Quarterly, 36(2), 242-263. https://doi.org/10.1123/apaq.2018-0068

Wilhelmsen, T., \& Sørensen, M. (2017). Inclusion of children with disabilities in physical education: A systematic review of literature from 2009 to 2015. Adapted Physical Activity Quarterly, 34(3), 311-337. https://doi.org/10.1123/apaq.2016-0017 